\title{
STENDHAL O LA ÉPICA DEL YO. Estudio comparativo de la autobiografía y la ficción
}

Antonio Bueno García

Desde que la crítica sociológica de la novela - a través de Lukács y Goldmann sobre todo- reveló el carácter comprometido del héroe y conceptuó su aventura como una «búsqueda de valores auténticos en un universo degradado ${ }^{»}$, el protagonista stendhaliano por antonomasia, Julien Sorel, fue considerado como el paradigma perfecto del individuo "problemático» y la obra en la que se enmarca, Le Rouge et le Noir, claro exponente del conflicto «héroe-mundo». Este nuevo planteamiento será la base en la que se cimente la narrativa moderna y representará su gran avance desde los tiempos lejanos de la épica.

Esta consideración «social» no debe sin embargo velar ni restar interés a la presencia de otro importante conflicto dentro de la narrativa stendhaliana, el del propio héroe contra sí mismo, contra las leyes que rigen su vida, contra su destino.

Estaríamos así entonces ante una nueva clase de épica, muy distinta a aquella que en forma poética celebraba la historia y las acciones gloriosas de un héroe y que suscitaba la admiración de todo un pueblo; ésta, desprovista ahora de carácter «poético» - al menos en lo que a la forma se refiere- y de grandeza -apreciación también relativa一, narra en primera persona la historia de un héroe en busca de sí mismo. La épica del "yo», como podríamos a partir de ahora denominarla, se convierte en la epopeya más auténtica y digna

1 Lucien Golomann, Pour une sociologie du roman, Galllimard, col. «Idees», 1964. 
de contar del alma humana, la que canta sus glorias y sus hazañas, sus desconsoladas tristezas y sus fracasos, y todo ello con arrojo y con un espontáneo y descarado narcisismo. «Fábula» en cualquier caso, fundamentada en la historia de un digno héroe, admirable, verosímil, y muy parecida a la de cualquier otro ser humano.

Los acontecimientos, las «gestas», tal y como eran entendidas en épocas anteriores, importan ahora poco, o muy poco, sólo en la medida en que tales acciones pueden afectar a la personalidad del héroe, a sus disposiciones mentales o a su escala de valores, a sus convicciones o a sus tremendas dudas; hechos éstos que serán desde ahora sus principales gestas.

Hacía ya muchos años —más de cuarenta — que se estaba fraguando en Stendhal el gran conflicto: una serie de fuerzas secretas y antagónicas venían luchando de manera insistente en el "yo" del autor, que le obligaban a vivir en un permanente estado de zozobra e inseguridad, como «en guerra» consigo mismo. El enemigo no siempre estaba declarado, unas veces parecía encontrarse fuera, era «el otro»: el padre —con quien debió librar batalla Brulard-, la hipócrita sociedad burguesa, la época en general... - a las que combatieron Julien Sorel, Lucien Leuwen o Fabrice del Dongo-; otras veces, al enemigo era menester buscarlo dentro de uno mismo, era el propio «yo», que se mostraba cambiante y vulnerable con el paso del tiempo y al que costaba retener.

Para luchar contra este estado de cosas, al escritor le caben dos soluciones posibles: o bien librar batalla abierta al adversario o adversarios, llamando al peligro por su nombre y enfrentándose a cualquier realidad por espinosa y dura que ésta sea (cosa que intentó hacer en su biografía); o bien, combatir de una manera velada al enemigo, por medio de otros frentes, a través de símiles y disfraces, como sucede en sus obras de ficción. En uno u otro proceso gusta Stendhal de utilizar la técnica del «camuflaje» o de la simulación para intentar burlar y despistar al adversario - «el otro» o el propio «yo»- y de paso también al lector. La simulación, que pretende abrir nuevas expectativas en la personalidad del «yo», se consigue escondiendo al propio «yo» en un «alter-ego», movimiento que enseguida da paso en la escritura al «heterónomo» - a ese otro nombre que designa al «otro" en el interior de uno mismo- y en la realización social al pseudónimo. Pronto vio Stendhal la necesidad de tal suplantación: 
Esta confesión del propio autor en su correspondencia, presagia lo que habría de ser la tónica general en toda su obra. Stendhal se sirvió de este disfraz incluso en su batalla más directa, la que libró bajo el nombre de Brulard.

El «pseudónimo», a la vez que un acto de simulación del propio nombre, puede ser también la evidencia de la negación de uno mismo. Si tomamos nota también de las distintas veces en que Henry Beyle, Stendhal, firmó diferentemente sus cartas, aparece que el autor cambió de nombre en casi doscientas ocasiones: el apellido Beyle lo abandonó enseguida, Brulard le traía malos recuerdos de la niñez, César Bombet o Stendhal —su pseudónimo que más triunfó y que provenía de una pequeña ciudad prusiana célebre por su carnaval- sólo eran episódicos... El abandono del nombre propio para adaptar otro diferente es un claro signo del deseo del autor de salir de un «yo» en el que se encuentra aprisionado y con el que no se siente realizado. Esta tendencia a construirse otra personalidad alternativa, a llenar su escritura de «dobles» es la estrategia más reiterativa y la más conseguida de este hábil conocedor de los movimientos del alma que fue Stendhal.

En medio de tal conflicto, el escritor se presenta sólo como simple espectador, un ser que se conforma con observar la batalla —eso sí, como si del mayor espectáculo del mundo se tratara-, y describirla a lo largo de sus páginas con aparente, aunque fingida serenidad.

Sin embargo, el engaño, la trama de intentar suplantar su propia personalidad y su propio «yo», enseguida se pone en evidencia y una simple biografía, una confesión, una carta ... una atención especial a su vida y a sus obras, basta para dejarla al descubierto.

A través de la escritura, el autor logra realizar ese gran «milagro» que es el contacto con el alma - «la escritura del alma habla siempre al alma», dirá Genette $^{2}$-, o con «Dios», como asegura Gusdorf ${ }^{3}$, cobrando así pleno sentido la teoría de su «función mediadora». Al igual que sucede con el «yo», la escritura se resiente también de su dualidad, de los «peligros» que la amenazan y anhela esa misma necesidad de «camuflarse», de parecer «otra» dentro de las rígidas formas a las que se ve sometida. También es probable, como ha señalado algún crítico $^{4}$, que el hecho de escribir implique siempre el desencanto de no poder escribir de otra manera.

2 Gérard GenetTe, Figures $I I$, Éds. du Seuil, col. «Tel Quel».

3 Para GUSDORF, la escritura autobiográfica responde a un pacto entre Dios y el que sólo se busca para encontrarle: "Toute littérature y compris la littérature du moi, est descendue du ciel sur la terre». G. GUSDORF, Lignes de vie: T1, Les écritures du moi, Odile Jacob, 1991.

4 Joaquim Sala-Sanahuja, "Del simulacro en la literaturaw, El Norte de Castilla, Letras, sábado, 2 de febrero de 1991 . 
La preocupación mayor de Stendhal, escritor, no fue nunca tanto buscar argumentos originales para sus novelas —que los recogía de aquí y de allá- como proyectarse en ellos y verse reflejado en cada página. Stendhal no negó nunca su desdén por la composición novelística, a la que dedicó incisivos desprecios, y en todo momento demostró preferirse a sí mismo frente a cualquiera de sus obras. El «espejo en el camino» resultó ser sobre todo un «paseante» por los rincones del alma, que iba reflejando sus movimientos más íntimos y secretos a la luz de la experiencia.

La costumbre de reflejarse en la propia obra es bastante común en el comportamiento de cualquier artista y puede que no resulte por ello demasiado novedosa en el autor, - la gran obra de arte adviene cuando el reflejo consigue deslumbrar al ser humano en general- Este arte llega sin embargo a tales cimas en Stendhal, confundiéndose de continuo con la vida y llegando al rincón más profundo del corazón del hombre, que no nos cabe ninguna duda: Stendhal es un gran artista, artista del autoconocimiento y del alma humana en general.

Es cosa comúnmente admitida que hablar de uno mismo, y de la manera más impúdica e indiscreta, puede ser también el mejor medio para ocultarse. El «egotismo» no es, según Genette, más que pura ostentación, «une parade ${ }^{5}$ », mera petulancia, una mentira. Parafraseando a Stefan $\mathrm{Zweig}^{6}$, «pocos hay que hayan mentido tanto, y con más pasión burlado al mundo, como lo hizo Stendhal, pero pocos hay también que hayan dicho más profundamente la verdad». Este hombre de Grenoble nos engaña hasta en su propia lápida funeraria, donde se hace pasar por «milanese»; cuando cita fechas, acontecimientos personales o sociales debe ser siempre considerado con cautela y muchas reservas, ese innato placer suyo por el disfraz, por deslumbrar en todo momento puede conducirnos pronto a error. A pesar de todo, también podemos decir con Zweig que pocos hombres han dicho al mundo tantas verdades acerca de sí mismos como lo hizo ese artista también del fingimiento.

El camino hacia el autoconocimiento es en verdad tarea ardua y espinosa, el escritor lo sabe bien cuando se propone iniciar la confesión («confiteor» viene de «fateon»-del indoeuropeo «for-fari»- que significa «decir la verdad», «declaran, "descubrir»). Hubo en su carrera literaria claros y decididos intentos de abordar en profundidad esta difícil tarea: lo hizo, primero en Souvenirs d'égotisme y casi acto seguido en Vie de Henry Brulard, cuando Beyle era ya

5 GenetTe, pág. 157.

6 Stefan Zweig, Obras completas. Biografías, (Stendhal), Clásicos Modernos, Ed. Juventud, Barcelona, 1952. 
un cincuentón, sin contar con las páginas de ese Diario —obra de juventudque le acompañó en muchos y delicados momentos de su vida o con esa sabrosa correspondencia - con su hermana Pauline, sobre todo- que nos descubren de continuo a un ser profundamente interesado en conocerse y hacerse conocer. El fondo y razón del «egotismo» stendhaliano - también llamado «beylismo»- y en definitiva de su tendencia autobiográfica, lo encontramos en su misma correspondencia:

«Me cito a menudo porque soy el hombre cuyo corazón conozco mejon ${ }^{7}$.

Espejismo del artista que, cuando de verdad se enfrente a la gran pregunta, no podrá por menos que admitir:

"Qu'ai-je été? Que suis-je? je serais bien embarressé de le dire..."

No obstante, por si acaso consigue averiguarlo, el autor se lanza a la gran tarea de escribir su autobiografía.

La autobiografía stendhaliana, representada sobre todo en Vie de Henry Brulard, aparece planteada - como sucede por lo general en casi todas- a nivel «de hecho», o de declaración de intenciones, y a nivel «estético» y «literario»; el primero se percibe tras el firme y comprometido deseo por parte del escritor de autoanalizarse para llegar así a conocer la verdad sobre sí mismo -aunque esto quede en pura fórmula y sea sólo en realidad una utopía-; y el segundo, el «estético» y «literario», por una intencionada búsqueda de verosimilitud en su narración y por el compromiso latente de un «pacto», no ya sólo entre el autor y el lector - a la manera del apuntado por Lejeune ${ }^{9}-$, sino entre el propio Beyle, nombre original del autor, y Brulard, el resultante de la confesión.

Los problemas con los que se va a encontrar la confesión son también muchos y de lo más variados; señalemos entre los más importantes el rechazo in-

7 Carta a Paulina, mayo de 1804.

8 STENDHAL, Vie de Henry Brulard, Gallimard, col. «Folio», 1973.

9 Philippe Lejeune, Le pacte autobiographique, Éds. du Seuil, col. «Poétique», 1975. 
consciente (o voluntario) de la propia personalidad, del propio «yo", y los derivados de la propia función $\longrightarrow$ mejor dicho, disfunción- de la memoria, aspectos éstos que en la mayoría de los casos habría que considerar más bien como mecanismos de defensa para evitar el dolor.

El primero, el rechazo del «yo», habría que ponerlo en relación con esa inadaptación del sujeto a asumir su propia identidad y con esa actitud ya explicada anteriormente del disfraz, del deseo de «camuflarse», de metamorfosear su nombre o su personalidad para parecer otro; el autor se busca a través de otras caras porque en realidad no está satisfecho con el individuo que le ha tocado interpretar.

En cuanto al segundo, la disfunción de la memoria, procede relacionarlo con el talante general del intimista. La memoria de Stendhal - como la de muchos autobiógrafos por lo general- es bastante precaria y caprichosa, y el escritor teme constantemente olvidar asuntos o acontecimientos importantes que hagan peligrar la «continuidad» de su vida -esa vida que es por lo demás su verdadero quehacer poético-, de ahí ese deseo de reflejar de inmediato sobre el papel cualquier sensación o emoción, cualquier secreto que pueda rescatarse del olvido. Ese carácter veleidoso de su memoria fue también materia de reflexión para el propio autor, que reconoció sin dificultad un despego absoluto de todo aquello que no tenía que ver con el mundo de sus sentimientos.

«Je ne prétends pas peindre les choses en elles-mêmes, mais seulement leur effet sur moi ${ }^{10}$ ».

Stendhal no aparece por eso ni tan siquiera en su autobiografía como testigo de los hechos; él no puede revivir los acontecimientos pasados sino los sentimientos que los mismos le procuraron. Sobre los reflejos del alma reconstruye el decurso de su historia; en vez de buscar, «inventa su vida», es decir, imagina los hechos según el recuerdo de sus sentimientos. Por eso hay mucho de novelesco en sus memorias, como mucho de autobiográfico en sus novelas.

Si nos centramos en dos de sus obras más significativas, Vie de Henry Brulard, de corte autobiográfico, y Le Rouge et le Noir, perteneciente al pretendido mundo de la ficción, observaremos de manera más clara esta interrelación de los dos polos, el autobiográfico y el novelesco, en el universo stendhaliano; notaremos que esa identificación entre el narrador y el autor, propia de la autobio-

10 Stendhal, Op. cit., ZWeig. 
grafía, se da también en la obra novelesca, y que existe un paralelismo asombroso entre algunos personajes de la ficción entre sí y entre estos mismos y algunos de la vida real del escritor.

¿Cuál es entonces la diferencia entre las dos formas de escritura? La principal y más sustancial estriba precisamente en su contrato de lectura: en la primera, la autobiográfica, se nos asegura a nosotros, el lector, que cuanto va a leer o escuchar es verdad, es fiel reflejo de una vida de la que su mismo autor se pone por testigo. La segunda, aparece exenta de esta sujeción moral y el lector es libre de sacar las conclusiones que quiera; la historia ha sido extraída del capítulo de "sucesos ${ }^{11}$ " y nada tiene que ver con la vida real del escritor $\longrightarrow$ al menos aparentemente, pues Stendhal, quiso diferenciar siempre su obra de la pura ficción por ese especial desdén personal hacia la obra novelesca-.

Siendo su planteamiento a todas luces diferente, no sucede así, sin embargo, en cuanto al fondo, las dos son la representación de la entrada de un héroe en el mundo: Vie de Henry Brulard relata la de este niño en medio de una familia hostil, con la presencia de un padre autoritario y ruin y con la desgracia inconsolable de la madre muerta; la segunda, Le Rouge et le Noir, narra otra entrada, en la incipiente edad adulta - casi precisamente cuando la anterior lo deja- y en medio de otro universo desfavorable, el de la propia sociedad burguesa de la primera mitad del siglo XIX y sus valores mezquinos. Familia y sociedad no serán más que dos vertientes de una misma realidad, la del mundo exterior al individuo, y serán campo de conspiración para los héroes. Las dos son representaciones igualmente de un fracaso, uno y otro protagonista, que se encuentran enfrentados a un mundo adverso, no consiguen superar los obstáculos y terminan sucumbiendo en su intento: Brulard no consigue la felicidad perdida, Sorel, no logra sus objetivos de ascenso en la vida y muere condenado por la misma sociedad a la que combate.

También a lo largo de las dos obras, se aprecian evidentes indicios, ciertas disposiciones mentales, que nos permiten corroborar lo ya expuesto sobre el paralelismo y la identidad existente entre las tres figuras del relato: autor, narrador, personaje.

En el relato autobiográfico, la identificación autor-narrador parece lógica por cuanto anteriormente se ha apuntado; llama ciertamente la atención esa postura de cambiar de nombre, ya lo hemos explicado también más arriba y no añadiremos nada nuevo sobre ese deseo de refugio de su personalidad, sólo destacar también ese deseo tan stendhaliano de «novelar» - en el mejor sentido del

11 La historia está sacada de la Gazette des Tribunaux donde se relata el intento de asesinato de Antoine Berthet en la persona de $\mathbf{M}^{\mathrm{me}}$. Michoud, el día 23 de febrero de 1828. 
término- para sacar de la monotonía y del encierro a una vida quizá considerada demasiado anodina.

Del narrador de Le Rouge et le Noir, destaquemos su presencia omnisciente en el relato, su posición privilegiada que le permite conocer a la perfección el decurso de la historia y la personalidad de sus protagonistas, especialmente la del héroe principal con cuya sensibilidad se identifica más claramente. Debemos considerarle como un puente, como un intermediario entre el héroe, joven y poco experimentado, que se deja llevar por los impulsos irracionales e idealistas propios de la edad, y el autor, ya cincuentón, maduro y desengañado de la vida, que se complace en recrear otra posible existencia, aunque termine recordándonos muchas veces la vida del propio Beyle. Sus comentarios sobre las acciones y la personalidad del héroe son ilustrativos:

«Julien s'obstinait à jouer le rôle d'un bon don Juan, lui que de la vie n'avait eu de maîtresse, il fut à mourir toute la journée ${ }^{12}$ ".

Sobre la identidad precisa del narrador, no es que tengamos muchos datos, pero los pocos que obran a nuestro alcance resultan útiles: sabemos, por ejemplo, que se trata de un habitante anónimo de Verrières, que se deleita en la contemplación del valle del Doubs desde lo alto del paseo que sigue $M$. de Rênal, al que reconoce sus méritos «quoiqu'il soit ultra et moi libéral» y a quien ve con un cierto atractivo que puede aún encontrarse «avec quarante ou cinquante ans» curiosamente la edad del escritor- pero en el que pronto se vislumbra «un certain air de contentement de soi et de suffisance mêlée à je ne sais quoi de borné et de peu inventif». No soporta el provincianismo, ni cuanto tiene que ver con el temperamento burgués o con el mundo del dinero. Conoce a la perfección el corazón de los personajes que cita y del hombre en general y también el alcance de las estrategias para llegar a él. Detrás de sus comentarios, se aprecia la sensibilidad de Julien Sorel, se adivina la transparencia enigmática del propio Stendhal.

Esta relación, tan característica en el universo literario stendhaliano, entre el narrador, el héroe y el propio autor ha sido considerada también por algún crítico como la «gran ironía» de este escritor al que siempre le gustó esconder su verdadera personalidad ${ }^{13}$.

12 Le Rouge et le Noir, Librairie Générale Française, col. «Le Livre de poche», pág. 89.

13 Michal Peled Ginsburg, «Stendhal: au-délà de l'opposition, la limite», Poétique, 83, sept. 1990, págs. 343-360. P. GinsBurg ve el mundo stendhaliano no ya sólo como un mundo de oposiciones, sino también de contradicciones. 
Beyle, Brulard, Stendhal, él mismo o casi él mismo en definitiva, están siempre presentes en su autobiografía o en sus novelas - del mismo modo que en sus ensayos, correspondencia o diario- y en perfecta comunión con su héroe de ficción, aunque ¿quién puede decir que estos nombres no pertenecen a ella?. Julien Sorel, Lucien Leuwen, Fabrice del Dongo... incluso el propio Henry Brulard, son almas paralelas del mismísimo Stendhal; cada una de ellas lleva en germen la personalidad del propio autor. Henry Brulard es la representación de un Beyle atormentado desde los años de la infancia; Julien Sorel - joven, atractivo, inteligente, impetuoso- es la proyección novelesca de los sueños de un Beyle de menguadas facultades donjuanescas y de alarmante inseguridad condenado a una tragedia absurda. Con prudencia y cautela - por un constante miedo a las humillaciones-, Julien Sorel intenta triunfar frente a la sociedad, como Brulard frente a su familia; ambos van esquivando los peligros que les acechan, que son para el joven Henry, su odiado padre y para Julien, la sociedad de su tiempo. A los dos les mueve un elevado idealismo, un entusiasmo por el mundo heroico (leen las memorias napoleónicas de Sainte-Hélène); tienen un espíritu ardiente y puro lleno de desbordante pasión por las mujeres (la madre o la amante); viven en la convicción de que deben refugiar su corazón en un mundo frío (Brulard en el silencio, Julien en la hipocresía), actitud que por otra parte les repugna; se rebelan contra el espíritu plebeyo y mediocre de una época entregada a valores mezquinos; poco a poco descubren las artimañas de sus enemigos, sus intrigas y se vuelven fríos, calculadores y extremadamente cerebrales. Todo como el mismo Stendhal.

Estos seres, como todos los de sus novelas en general, son el resultado de la «alquimia» del escritor, una alquimia que consiste, como señala Consuelo Berges $^{14}$, en «transfundirse el mismo en unos seres de su propia creación que serán siempre jóvenes y que realizarán la fórmula ideal de su propio sentir la juventud», en repetir, como en el caso de Brulard, el tiempo de la infancia para intentar reconocerse cuarenta años después. El autor vivirá en sus héroes «por procuración».

Beyle, en efecto, está siempre presente, pero nada será más vano que pretender encontrar en sus escritos - como en los testimonios incluso de sus contemporáneos- los trazos de un ser definido y coherente. A través de todas sus vidas -reales o imaginarias - y a cualquier nivel de su experiencia literaria en general, Stendhal se muestra «doble» y desconcertante como sus propios héroes. Esta dualidad será sin embargo más claramente perceptible en los escri-

14 Consuelo Berges, Stendhal y su mundo, Alianza Editorial, 1983. 
tos autobiográficos que en el resto, porque en ellos se produce ese diálogo constante entre los dos «yo» (tan poco halagüeño para quien se busca con la intención de encontrarse idéntico y coherente), que llenará de frustración y de impotencia al autor y desorientará tremendamente al lector.

Los paralelismos no solo se producen entre la personalidad del ente narrador y la del autor, o entre la de éstos y la del héroe principal, sino también entre los personajes mismos de una y otra obra. Dejando a un lado el paralelismo evidente entre Julien y Brulard, podría hablarse de un trasvase de personalidades, de una proyección recíproca de personajes en el marco de las dos obras. En primer lugar deberemos señalar la presencia en ambas de ciertos seres que podríamos catalogar como «benéficos» o "positivos» en el universo del héroe -que coinciden en Vie de Henry Brulard en su mayor parte con los familiares de la línea materna, y en Le Rouge et le Noir con la presencia femenina, de $\mathbf{M}^{\text {me }}$. de Rênal sobre todo, o la de algún otro personaje más secundario como el cura Chélan-; y otros «negativos», relacionados con el universo del padre, en la primera, y con el mundo burgués y religioso (del Seminario) en la segunda.

Entre los primeros, los «benéficos» o «positivos», cabría situar en el universo de Brulard a Henriette Gagnon, su madre, «tendre» y «douce», de la que el hijo estaba profundamente enamorado y que reúne las más altas cualidades humanas; personaje comparable en el universo de Julien a $M^{m e}$. de Rênal, "très belle et très sentimentale» que personificará enseguida la pasión; igualmente hay que tener en cuenta en el universo favorable de Brulard a Henri Gagnon, abuelo materno del niño, que cumple la función de verdadero padre y de amigo íntimo, a quien debe cuanto él sabe, y a tía Elisabeth, hermana del anterior; estos personajes encuentran digna proyección en Le Rouge et le Noir en el cura Chélan (de idéntico nombre al abate que aparece en Vie de Henry Brulard), «homme probe et honnête», que se encarga de su primera educación y le advierte de los peligros de la vida, o incluso en el marqués de la Mole representante de los valores nobles - mucho más dignos que los burgueses- a quien deberá su ascenso social.

Entre las presencias «negativas», ocupa un lugar importante dentro de la vida de Brulard, el padre, Chérubin Beyle, aborrecido por su hijo y merecedor de los más reprobables calificativos; y junto al padre, toda una serie de personajes odiados en su nombre: el abate Raillane tenebroso canalla, merecedor del elocuente título «tiranie Raillane»; Séraphie, hermana del padre y sustituta de la madre; Zénaïde "parce qu'elle était chérie par mon père qui chaque soir l'endormait sur ses genoux et hautement protégée par Mlle. Séraphie». En el espacio vital de Julien Sorel estos valores negativos estarán representados también en la persona del padre, M. Sorel, serrador, iletrado como el 
resto de sus hijos, que desprecia y maltrata al héroe; $M$. de Rênal, «celui de la parole dure», alcalde de Verrières, de carácter agrio y despótico, representante de los valores mezquinos; $M$. Valenod, esbirro del anterior; Madame Derville, recuerdo de tía Séraphie, que se interpone entre el amor de $\mathbf{M}^{\text {me }}$ de Rênal y Julien.

El personaje de Mathilde de la Mole merece quizás una atención especial, pues en él se descubre como coinciden en señalar algunos críticos, rasgos de la personalidad del propio Julien; es la depositaria de su misma sensibilidad y de su misma audacia; Henri Martineau, a quien debemos el prefacio de la primera edición de Le Rouge et le Noir, nos la presentaba ya como «aquella angelical mujer que reunía en sí todas las perfecciones de una adorable sensibilidad con la energía que hace a las personas capaces de las acciones más sublimes». Es como una hermana de carácter y de experiencias para Julien y para el mismo autor, y por ello podría comparársela a la misma Pauline Beyle, su gran amor fraterno, a quien el escritor daba reglas y minuciosos consejos sobre el «arte de vivir».

Al igual que advertimos la existencia de paralelismos entre personajes de ambas obras, los encontramos también entre ciertas situaciones de las mismas: uno de los grandes remordimientos de la primera juventud de Brulard fue no haber podido consumar un duelo con un muchacho grandullón (por haberse avenido a razones) como de alguna manera sucede en Le Rouge et le Noir con el capitán Burelviller, que no toma en serio el gesto fiero del bisoño Julien; recuérdese también el célebre episodio de la caída del caballo en casa del marqués de La Mole, que había vivido Beyle a los diecisiete años. Pero no sólo pueden verse paralelismos entre situaciones vividas por Brulard o Julien, también aparecen, por ejemplo, con Mathilde en Le Rouge et le Noir: ésta escamotea, por ejemplo, uno a uno los cuatro tomos de Voltaire como había hecho Henry Brulard. Algo mucho más interesante sucede cuando un mismo personaje de una obra atraviesa directamente el umbral de la otra:

\author{
«Je dirais comme Julien: Canaille! Canaille! Canaille!». (Vie de \\ Henry Brulard)
}

Resulta también que los personajes y las situaciones de la obra de ficción son un calco a veces de la propia vida personal del autor (damos por descontado que los hechos narrados en su autobiografía responden más o menos fielmente a las circunstancias de su vida personal). Así por ejemplo, nos consta por los biógrafos del autor, que la posición frente al marido de la condesa Daru 
(amante largo tiempo pretendida por Stendhal) resultaba similar a la del personaje de $\mathbf{M}^{\text {me }}$ de Rênal; o que el perfil de esta última está inspirado en la experiencia de su amor con Mathilde Viscontini, el único amor-pasión de su vida; que Alberte de Rubempré (prima y parece ser que algo más de Delacroix), amante fugaz de Stendhal, aparece muy bien definida en los rasgos de Mathilde de La Mole (la dama incluso se daba por aludida cuando Stendhal le leía pasajes de Le Rouge et le Noir; que la anécdota de aquel encierro del propio autor en una bodega del castillo de Clementine Curial, su amante del momento, se la transfiere a Julien Sorel en Le Rouge et le Noir.... Pero éstas son cosas muy normales en el oficio de un escritor de la propia experiencia personal como lo fue Stendhal.

Gilbert Durand sugiere en la lectura stendhaliana la presencia de una serie de temas que podrían considerarse "recurrentes» - por su frecuente manifestación e importancia en el universo literario del autor-y que podrían ser: la reflexión sobre sí mismo (la de un «yo» equiparable al autor o la de un «él» que se identifica plenamente con el narrador omnisciente y el autor); la soledad y las pruebas cualificadoras a las que se ve sometido el héroe; los valores de la familia y de la sociedad... Sin duda, a éstos merecen añadirse otros no menos reiterativos y que creemos serían el amor y la muerte.

El amor aparece como la preocupación esencial para estos dos héroes, Henry Brulard y Julien Sorel. Se trata de un amor de idéntica naturaleza que su propia gloria, y en él encuentran la razón de su existencia; el pequeño Henry vive movido por el recuerdo imborrable del amor hacia su madre, un amor platónico e incestuoso, que no tiene deseo alguno de ocultar y que es la razón de sus continuas luchas con el padre - su caso ha sido siempre considerado como uno de los más claros «edipos» de la historia de la literatura - . La imposibilidad de ver realizado tal amor vuelve a aparecer en la relación mantenida por Julien Sorel con $\mathbf{M}^{\text {me }}$ de Rênal.

En Le Rouge et le Noir el amor tiene una doble lectura: por un lado, aparece como una proyección de los deseos de ascenso social del individuo y de sus artimañas para conseguirlo, y por otra, como realización de un sentimiento prohibido y vital en la historia del autor. El amor sería, según la primera interpretación - la ya clásicamente extendida-, un sentimiento práctico, que le permite al héroe ascender en sociedad y tomarse la revancha de sus anhelos frustrados; un campo de experimentación táctica, en el que hay mucho en juego y en el que el héroe puede fácilmente sucumbir, de ahí que se tenga en cuenta el peligro: 
«Elle est bonne et douce, son goût pour moi est vif, mais elle a été élevée dans le cap ennemi ${ }^{15_{\text {}}}$.

La proyección del amor prohibido, materno, en el que se descubre la historia íntima y la experiencia del propio autor, no nos parece menos interesante.

La relación con Mme de Rênal nace inconscientemente bajo la eufemística definición de «ternura maternal»,

"Que voulez-vous ici, mon enfant? ${ }^{16}$ ".

Son las primeras palabras que $\mathbf{M}^{\mathrm{me}}$ de Rênal dirige al tímido Julien que llama a su puerta. El mundo del amor materno y de la infancia empapa de contenido las primeras páginas de esta nueva aventura que es Le Rouge et le Noir. $\mathbf{M}^{\mathrm{me}}$ de Rênal empieza confundiendo al que será su amante con un niño,

«elle aperçut près de la porte d'entrée la figure d'un jeune paysan presque encore enfant ${ }^{17}$ ».

Y cuando el amor ha entrado en su corazón, le viene en ocasiones la ilusión de amarle como a un hijo.

«ll y avait des jours où elle avait l'illusion de l'aimer comme son enfant. Sans cesse n'avait-elle pas à repondre sur mille chose simples qu'un enfant bien né n'ingnore pas à quinze ans ? ${ }^{18}$ ".

La preocupación esencial de esta madre parece ser también el trato que el nuevo maestro dispensará a sus hijos:

15 Le Rouge et le Noir, pág. 99.

16 Somos nosotros quienes resaltamos la palabra «enfant». Le Rouge et le Noir, pág. 33.

17 Le Rouge et le Noir, pág. 32.

18 Idem, pág. 126. 
- ... «vous ne donnerez pas le fouet à mes enfants, même quand ils ne saureient pas leurs leçons ${ }^{19} n$.

- «Vous ne gronderez pas trop ces pauvres enfants? ${ }^{20}{ }_{\gg}$

- «Vous serez bon pour eux, vous me le promettez ${ }^{21} »$.

- «Une fois son père a voulu le battre, l'enfant a été malade pendant toute une semaine... ${ }^{22}$ ».

No es preciso señalar cuánto nos recuerdan estos temores a los que tenía Henriette Gagnon por su hijo.

La imagen del padre horrible y autoritario, dispuesto a reprimir el amor de su hijo y contrincante vuelve a estar también presente ahora, doblemente, en la figura de M. Sorel, padre del protagonista:

«Réponds-moi sans mentir, si tu le peux chien de lisard; d'où connais-tu madame de Rênal, quand lui as tu parlé? ${ }^{23}$ ".

— «Mais tu l'auras regardée, vilain effronté ${ }^{24} »$.

y en la figura del esposo, M. de Rênal.

$\mathbf{M}^{\text {me }}$ de Rênal encarna al tipo de mujer que Julien Sorel (Henry Brulard o Stendhal) ama - siempre parecida a la madre - y por quien querría ser amado.

El amor de Mathilde recuerda -igual que su temperamento- al de Julien; en efecto, se trata de un amor «táctico», que tiene para el héroe como finalidad probarse en su audacia. Mathilde escoge a Julien por ser éste inferior y poseer energía y determinación; Julien hace lo propio con ella por elevar su rango social con alguien de categoría superior y porque ésta se lo permite. Uno y otro expresan sus mismos anhelos, se mueven por el mismo interés y su amor no traerá consecuencias graves para ninguno de los dos.

\footnotetext{
19 Idem, pág. 35.

20 Idem, pág. 33.

21 Idem, pág. 34.

22 Idem, pág. 35.

23 Idem, pág. 25.

24 Ibidem.
} 
Junto al sentimiento del amor está siempre el deseo. El despertar del mismo se remonta tan atrás como la propia existencia del autor. Los deseos reprimidos del «yo», como los celos, han sido objeto de un gran estudio por parte de René Girard, que basó tal conflicto en lo que él denominaba «deseo triangular ${ }^{25}$ ", deseo provocado siempre por un tercero, y que aumenta en intensidad cuanto más difícil resulta de satisfacer. La conciencia de clase, como el amor maternal, reavivan los deseos, y el héroe -el «yo» mediatizado por la acción o presencia del «otro» (el padre, el burgués...) - se ve sumido en un torbellino de pasiones imparable. En la obra de Stendhal, estas manifestaciones se traducen, como el mismo Girard apunta, en gestos de "agresión» a las mujeres (hacia $M^{\text {me }}$ de Rênal, Mathilde, Séraphie...), que son respondidos inmediatamente por la familia o por la sociedad con el reproche $y$ con el castigo.

La familia - por medio aquí del padre-, la sociedad burguesa - a través de su concepción restringida de la justicia -, la Iglesia —-por el respeto que reclama a las leyes divinas-, hacen fracasar el amor y los deseos respectivamente del hijo, de las clases inferiores y de quien osa traspasar el umbral de lo razonable y de los valores eternos, y la muerte, presente siempre en ambas obras, viene a poner fin a tan desdichada y atrevida aventura.

La muerte es, sin duda alguna, otro de los temas siempre presentes en la poética stendhaliana, y uno de los más controvertidos. En Vie de Henry Brulard, actúa como desencadenante del conflicto - más aún que el amor, que quizá viene propiciado por ella-. Esta muerte es incomprendida,

... «il me semblait que je la reverrais le lendemain, je ne comprenais pas la mort ${ }^{26} \gg$.

El niño no puede llorar - reproche que le hace tía Séraphie - porque no ha asimilado la pérdida de la madre.

En Le Rouge et le Noir, esta muerte aparece como resultado, al final de la obra, aunque ya viene estando presente desde el principio del relato: un sentimiento planea, por ejemplo, al encontrar Julien en la Iglesia una página de periódico olvidada donde lee: «Détails de l'execution et des derniers moments de Louis Jenrel, exécuté à Besançon, le...» y al salir cree ver sangre en

25 René GIRARD, Mensonge romantique et vérité romanesque, Hachette, Pluriel, 1978.

26 Vie de Henry Brulard, pág. 53. 
la pila de agua bendita, cuando sólo era el reflejo de las cortinas rojas sobre las ventanas.

Mucho se ha discutido sobre el sentido de esta muerte - la del propio héroe- Si muere, creemos, es porque para el autor no existe otra solución posible para tal conflicto. La muerte es la única y definitiva respuesta a ese amor imposible. Las tácticas de Julien -como las de Napoleón- terminan sucumbiendo igual que el propio héroe. El horror de su amor y de su acción no podía encontrar otra solución; la sociedad, ¿qué otra cosa podía hacer que condenar al instigador proveniente de las clases inferiores?

Los protagonistas terminan asumiendo los defectos que se les imputan, que es otra manera de morir también: el pequeño Henry termina por aceptar lo que en nombre del padre se le reprocha y se dice "mauvais fils», «criminel», «mechant malheureux», "l'étre le plus sombre»...,

“Quant à moi j'étais aussi criminel que possible, j'aimais ses charmes avec fureur ${ }^{27}$ ».

y Julien Sorel la sentencia que la sociedad le imputa:

«J'ai été offensé d'une manière atroce; j'ai tué, je mérite la mort, mais voilà tout. Je meurs après avoir soldé mon compte envers l'humanitén.

\section{(...)}

«Avant de finir, Julien revint à la préméditation, à son repentir, au respect, a l'adoration filiale et sans bornes que, dans les temps plus heureux, il avait pour Madame de Rênalm.

Los fracasos de Julien como los de Henry se deben más a errores de apreciación sobre su propia personalidad y sobre el mundo, es decir, a una cuestión meramente práctica que a una falta de táctica o de inteligencia -que en sus héroes es desbordante- Como él mismo escribe en su Diario, el 10 de diciembre de 1801:

27 Vie de Henry Brulard, pág. 53. 
«Presque tous les malheurs de la vie viennent de fausses idées que nous avons sur ce qui nous arrive. Connaitre à fond les hommes, juger sainement des évenements, est donc un grand pas vers le bonheurs.

Como la aventura del héroe - el amor-, la escritura también lleva el estigma de la muerte; el final de Henry Brulard es bastante significativo:

«On gâte des sentiments si tendres à les raconter en détail ${ }^{28}$ ».

La experiencia autobiográfica —en un alma que pretende autoconocerse- fracasa, como ocurre en un género de pretensiones más veladas, el de la obra novelesca. Pero esta muerte, decisión fatal del héroe stendhaliano y de la escritura, es también - y aquí creemos está lo más importante - un medio de purificación. El amor es la única emoción capaz de superar el odio. Frente al amor ambicioso y revanchista, representado sobre todo en su relación con Mathilde, está el amor puro que le termina inspirando Madame de Rênal, y que en el momento de la muerte le hace sentirse reconciliado consigo mismo. La muerte simboliza también un regreso al «útero», como diría el psicoanálisis, a la realidad primera - su entierro en la cueva de una montaña vecina parece significativo- y su paso será decisivo para la autorrealización del héroe.

El fracaso aparente de la escritura - más bien de la aventura- coincide con el éxito del escritor, que ha conseguido vencer a sus fantasmas y dominar su empuje. El hecho de escribir su vida o sobre su vida, de reconocerse en el pasado y en el presente al mismo tiempo, le permite aproximarse por la escritura al centro de sí mismo.

Vie de Henry Brulard es la vía de una rebelión encaminada a su autoconocimiento y a su autocorrección; Le Rouge et le Noir el de la realización de un sueño. Tanto Brulard como Sorel se hacen a través de la misma escritura; escritura que para uno representará el refugio contra la fealdad paterna y para el otro será la materialización de una quimera.

La creación literaria compensa al autor de las decepciones y de las mezquinerías de la vida y le permite buscar una salida a su propio destino. La autobio-

28 Vie de Henry Brulard, pág. 435. 
grafía o la ficción novelesca, con idéntico objetivo, pero con medios diferentes, unen sus empeños para liberar el alma del escritor y ponerle en el camino del conocimiento, que representará su felicidad.

En uno y otro frente, el «yo» ha conseguido salir victorioso en su aventura épica. 